\title{
Sex differences and reasoning vs. imagery strategies in the solution of visually and auditorily presented family relationship problems
}

\author{
PAUL BIRKETT \\ Bolton Institute of Technology, Deane Road, Bolton BLS 5AB, Lancashire, Great Britain
}

\begin{abstract}
Twenty males and 20 females solved family relationship problems of the type "what relation is she to her mother's father's brother?" Ten subjects of each sex were read the problems, and 10 of each sex had them presented visually. Females manifested shorter solution times in both presentation conditions but only significantly so in the auditory condition. Subjects reported using a mental image of a family tree more often in the auditory condition than in the visual condition; there were no sex differences in the use of such a strategy. Various possible explanations for these findings are advanced and discussed within the context of the development of problem solving strategies. It is concluded that females probably have an advantage with these particular problems.
\end{abstract}

The purpose of the experiment to be described below was to examine whether visual and auditory presentation of family relationship problems such as "what relation is she to her father's mother's brother?" resulted in the same pattern of performance in males and females. Wood and Shotter (1973) report that females are superior at solving problems of this type whereas Wood, Shotter, and Godden (1974) found that males are better able to solve series problems of the kind "who is tallest, Fred or Bill, if John is taller than Pete, Bill is faller than John, John is taller than Fred?" Both types of problem involve deductive reasoning and it seems incongruent that males and females perform differently in this way. However, it is of note that the series problems were presented visually whilst the family relationship problems were read to subjects. This variable may have contributed to the opposing relative performances of males and females with the two problem types, and one aim of the present study was to investigate whether this was so.

A related point of interest is whether sex of subject and mode of problem presentation affect the nature of the strategies used by subjects to aid them in problem solution. Wood and Shotter (1973) found, using family relationship problems, that subjects tended to rely on some form of imaginal representation of a family tree during the task. Spatial imagery is also reported to occur in subjects solving series problems; DeSoto, London, and Handel (1965), Handel, London, and DeSoto (1968), Hunter (1957), Huttenlocher (1968) and Wood et al. (1974) all report that subjects construct imaginal spatial representations of the relations between problem elements.

Clark (1969a, b; 1971), however, maintains that

The author thanks Mr. K. Beswick for his help in running the subjects and Dr. S. E. Newstead and Dr. R. H. Ranyard for their comments on an earlier draft of this paper. Lee $R$. Brooks sponsors this paper and takes full editorial responsibility for its content. before some kinds of problems can be understood they must be transformed so as to reveal their deep strucutre; that is, subjects deal with them in terms of their meaning. In view of these differing accounts, it was decided, as a second aim of this experiment, to examine, using subjects' introspections, the nature of the strategies employed during the problem solving task and the effects of sex of subject and mode of problem presentation on the nature of such strategies. With respect to the sex variable, we note that Wood et al. (1974) question whether females do, in fact, use spatial images as an aid to problem solving since they were less able than males to answer unexpected "probe" questions, especially earlier in the experimental session; in addition, they made more "relational" errors than males, whilst still being able to recall the problem elements.

Whilst we expected females to prove more efficient at solving the problems in both presentation conditions, we made no predictions as to the effects on subjects' strategies of sex of subject and mode of problem presentation.

\section{METHOD}

\section{Subjects}

Subjects were 40 undergraduates at Bolton Institute of Technology, 20 male and 20 female. Ten subjects from each sex group were assigned to the visual presentation condition, and, similarly, 10 from each sex group were assigned to the auditory presentation condition.

\section{Materials}

The 20 problems (shown below) were photographed onto slides for the visual condition and presented on a white paper screen by means of a tachistoscopic slide projector. In the auditory condition. the problems were read to subjects. The procedure in both conditions was recorded on tape, and subjects were aware of this fact. In both conditions, the wording preceding the problem elements took the same form, i.e., "What relation is he/she to: (1) her sister's daughter? (2) his father's brother? (3) her mother's mother? (4) her mother's sister? (5) his father's father? (6) his brother's son? (7) his father's brother's son? (8) her mother's 
Table 1

Mean Solution Time Per Problem (in Seconds) for the Four Experimental Groups

\begin{tabular}{lccl}
\hline & Male & Female & \\
\hline Visual & 8.17 & 7.05 & $\mathrm{p}>.05$ \\
Auditory & 5.11 & 3.43 & $\mathrm{p}<.025$ \\
\hline
\end{tabular}

sister's daughter? (9) his father's father's brother? (10) her mother's mother's sister? (11) his sister's daughter? (12) her father's brother? (13) her father's mother? (14) his mother's sister? (15) his mother's father? (16) his sister's son? (17) his mother's sister's son (18) her father's brother's daughter? (19) his father's mother's brother? (20) his mother's father's sister?"

\section{Procedure}

Problems were presented in a different random order for each subject. In the visual condition, subjects were seated facing a white paper screen in a suitably darkened sound proof booth. A distinctive click issued from the slide projector synchronous with the appearance of a problem on the screen. This set the occasion for starting to time the subject. Timing ceased as soon as the subject had given his, her answer. whether right or wrong.

In the auditory condition. problems were read to subjects whilst they were seated opposite the experimenter. Timing began as soon as the last word of the problem had been read and ceased when the subject gave an answer. The timing of response latencies was completed postexperimentally using the tape recordings.

Instructions to subjects were: "I am going to present to you a series of 20 family relationship problems in which your task is to work out how two people are related. They will be of the nature "what relation is he/she to his/her... ?" (Here, two sample problems were inserted to familiarize the subject with the type of problem.)

After determining that the subject understood the instructions. the experiment proceeded. When the subjects had answered a problem. they were asked if they were ready to go on to the next one. After the session was over. subjects were asked to explain how they had gone about solving the problems and this was followed by any questions from the experimenter necessary to clarify subjects statements. The whole session took roughly $30 \mathrm{~min}$.

\section{RESULTS}

As expected, most subjects were able to give correct answers to most of the problems; this meant that error scores were not a good measure of problem solving ability and therefore solution times were used instead. (One male subject in the visual condition displayed very atypical error scores, only solving 4 of the 20 problems correctly; his nearest "rival" scored 13 out of 20. For this reason, the former subject's data were not included in the analyses of sex difference.)

\section{Sex Differences}

The average time taken to solve a problem in each condition for males and females is given in Table 1. In the auditory condition, females achieved significantly shorter solution times $(t=2.37$, $d f=18, p<.025$, one-tailed). In the visual condition, the difference between the mean scores of males and females, though again in the direction of female superiority, did not achieve significance $(t=1.32, \mathrm{df}=17, \mathrm{p}>$ .05 , one-tailed).

\section{Subject's Strategies}

Of the 40 subjects who were asked about their strategies, 26 mentioned the use of some form of mental image in the shape of a two-dimensional family tree structure with descendancy represented on the vertical axis and colinearity on the horizontal axis. The other 14 subjects not reporting such well-defined imagery described "working one step at a time," or, "using my own family" or other, more idiosyncratic methods.

The "family tree strategy" was used by 18 of the 20 subjects in the auditory condition and by 8 of the 20 subjects in the visual condition; this difference reached significance on the Chi Square test $\left(\chi^{2}=10.9\right.$, $\mathrm{df}=1, \mathrm{p}<.002$, two-tailed).

There was, however, no significant sex difference in the incidence of this imagery; it was reported by 12 out of the 20 males and by 14 of the 20 females $\left(\chi^{2}=.26\right.$, $\mathrm{df}=1, \mathrm{p}>.5$, two-tailed).

\section{DISCUSSION}

We have shown here that auditory and visual presentation of family relationship problems results in a female superiority in terms of time to solution which is, however. significant only in the auditory condition. It seems. therefore, that the mode of problem presentation does have an effect on the sex difference in performance, albeit on the magnitude of this difference rather than on the direction.

In contrast to the finding of Wood et al. (1974) with series problems. males were not superior under conditions of visual presentation, although female superiority was reduced. Whilst we feel, for reasons to be discussed below, that the two kinds of problem are not truly comparable, it is worth noting that differential stimulus saliency for males and females may have contributed to females reduced superiority in the visual condition. There is evidence that males are more sensitive than females to visual input whilst the reverse is true for auditory stimuli (Kagan. 1969: Money, 1963; Simner, 1971: Watson, 1969), especially spoken language (Buffery \& Gray. 1972; Kimura. 1963; Such differential sensitivity could only have had a minimal influence in the present study, however.

Although there was no sex difference in the use of the family tree mental image. our results show that such an image was employed more frequently in the auditory condition than in the visual condition. There are two possible factors which might have produced this difference. Firstly. in the visual condition. each problem was displayed for as long as it took the subject to solve it. In the auditory condition, a problem was read aloud once only, thus necessitating that the subject remember it. The greater incidence of visual imagery in the auditory condition may have been the result of visual imagery in the auditory condition may have been the result of subjects using such inagery as a means by which they remembered the problems. Secondis. there is evidence to show that the act of reading is not compatible with the act of imaging (Brooks, 1967). Since in the visual condition each problem was displayed until the subject answered. 11 is probable that imagery was given little chance (1) evole spontancously. We note that Huttenlocher 11968). who describes subjects using imagery to solve series problems. also read the problems to them.

Mental imagery in the form of a family tree structure was mentioned only infrequently in the visual condition then. The problems were displayed in the form of a two-line sentence and the inaginal ordering of the problem elements would depend on the terms involved in that particular problem. Series problems, on the other hand. are usually displayed with the premises underneath each other, or. in the case of three-term series problems. next to 
each other with the question underneath. It is this perceptual inidriance in the problem display which Quintor ard Fellow's (1975) find their subjects using as a basis for easier and quicker perceptual strategies. Their evidence, and that of Wood and Shotter (1973) and Wood et al. (1974). tends to support Johnson-Laird's (1972) suggestion that whereas subjects will initially think about the meanings of problem elements they will. as they gain experience with them. move to using invariant features they discover as a foundation for the imaginal spatial ordering of the problem elements. This seems to reconcile the "thinking" vs. "visualizing" argument outlined in the beginning of this paper; the fact is that both types of strategy occur. Quinton and Fellows report a further formalization of this process involving purely perceptual invariances.

With our visually presented family relationship problems, it is likely that subjects never reached this perceptual strategy since the nature of the problems does not allow them to be presented as an organized display. It is also apparent that subjects found it difficult to construct spatial images to aid them in problem solving in the visual condition. These two factors combined make it probable that subjects had to rely more on "thinking" strategies in this condition than in the auditory condition. Whilst the timing procedure in the tw o conditions was not identical and therefore a direct comparison is not truly valid. we note that solution times in the visual condition were almost double those in the auditory condition: whether this was entirely due to the length of time it took subjects to read the problems requires experimental investigation.

Our problems clearly possess an "abstract relational structure" in that they all involve a consideration of kinship terms which can be ordered along the lines of descendancy and colinearity. Romney and D'Andrade (1964) suggest that each individual possess a cognitive map of kinship terms which forms the basis for the everyday use of such terms. Subjects in our auditory condition might well have been using such a semantic representation when they formed their mental images of family trees. It seems probable that females possess a more extensive and easily accessible cognitive map of kinship terms than males and hence will have an inherent superiority with the problems we used; certainly there is much evidence that females are more interested in family affairs (Carlson, 1971: Gutmann. 1965: Little. 1968). It would be interesting to investigate the way in which strategies develop in solving these problems. to see if females more rapidly develop more efficient strategies.

As to females reduced superiority in the visual condition, this might be a consequence of their being forced to use thinking strategies. The w'ork of Witkin, Dyk, Faterson, Goodenough, and Karp (1962) has shown that males are better able to resist a visually distracting influence. Thus while thinking through these problems, males might be more able to resist distraction from the visual presentation of the problems. This, combined with males' superior verbal reasoning ability (Bennett, Seashore, \& Wesman, 1959; Tyler. 1965) could have served to reduce an inherent female superiority.

\section{CONCLUSIONS}

We have shown here that females achieve shorter solution times than males when solving family relationship problems in both auditory and visual presentation conditions, but only significantly so in the former. We have attempted to explain these differences by (a) citing evidence which shows that males and females deal more efficiently with visual and auditory (especially verbal) material respectively; (b) suggesting that females have an inherent superiority with family relationship problems; (c) proposing that females' reduced superiority in the visual condition results from their competing with males who are better able to resist the visual distraction of the problem display and who find it easier to use verbal reasoning which, we feel, is a strateg! both sexes are forced to use in this condition.

We have also found that visual imagery in the form of a family tree structure was used more in the auditory condition. Such imagery is, we have suggested, more likely to occur, perhaps as an aid to memory. if subjects are not involved in reading the problems. Because of the difference between the visual display of series problems and family relationship problems we feel that the development of strategies to solve the two types of problem will not take the same ccurse, so that the treatment of the two types as involving similar strategy development will prove misleading.

Much could be learned from an investigation of the nature and development of problem solving strategies in males and females using different kinds of problems presented in different ways. The present study emphasizes the need to consider both the type of problem and its mode of presentation when investigating sex differences and strategies in problem solving.

\section{REFERENCES}

Bennett, G. K., Seashore, H. G., \& Wesman, A. G. Differential aptitude tests (3rd ed.). New York: Psychological Corporation, 1959.

BRooks, L. R. The suppression of visualization by reading. Quarterly Journal of Experimental Psychology, 1967, 19, 289-299.

Buffery, A. W. H., \& Gray, J. A. Sex differences in spatial and linguistic skills. In C. Ounsted \& D. C. Taylor (Eds.), Gender differences: Their ontogeny and significance. Edinburgh: Churchill Livingstone, 1972.

Carlson, R. Sex differences in ego functioning: Exploratory studies of agency and communication. Journal of Consulting and Clinical Psychology, 1971, 37, 267.277.

Clark, H. H. Linguistic processes in deductive reasoning. Psychological Review, 1969, 76, 387-404. (a)

Clark, H. H. The influence of language in solving three-term series problems. Journal of Experimental Psychology, 1969, 82, 205-215. (b)

Clark, H. H. More about adjectives, comparatives and syllogisms': A reply to Huttenlocher and Higgins. Psychological Review, 1971, 78, 515-527.

DeSoto, C. B., London, M., \& HANdel, S. Social reasoning and spatial paralogic. Journal of Personality and Social Psychology, 1965, 2, 513-521.

Gutmann, D. Women and the conception of ego strength. Merrill Palmer Quarterly, 1965, 11, 229-240.

Handel, S., London, M., \& DeSoto, C. B. Reasoning and spatial representations. Journal of Verbal Learning and Verbal Behavior, 1968, 7. 351-357.

Hunter. I. M. L. The solving of three-term series problems. British Journal of Psychology, 1957, 48, 286-298.

Huttenlocher, J. Constructing spatial images: A strategy in reasoning . Psychological Review, 1968, 75. 550-560.

Johnson-Laird, P. N. The three-term series problem. Cognition, 1972, 1, 57-82.

KAGAN, J. On the meaning of behavior: Illustrations from the infant. Child Development, 40, 1121-1134.

KIMURA, D. Speech lateralization in young children as determined by an auditory test. Journal of Comparative and Physiological Psychology, 1963, 56, 899-902. 
Little, B. Psychospecialisation: Functions of differential interest in persons and things. Bulletin of the British Psychological Society, 1968, 21, 113.

Money, J. Cytogenetic and psychosexual incongruities with a note on space-form blindness. American Journal of Psychiatry, 1963, 119, 820-827.

Quinton, G., \& Fellows, B. J. 'Perceptual' strategies in the solving of three-term series problems. British Journal of Psychology, 1975, 66, 69-78.

Romney, A. K., \& D'ANDRADE, R. G. Cognitive aspects of English kin terms. American Anthropoligst, 1964, 66, 146-170.

Simner, M. L. Newborn's response to the cry of another infant. Developmental Psychology, 1971, 5, 136-150.

TYLER, L. The psychology of human differences (3rd ed.). New York: Appleton-Century-Crofts, 1965.
Watson, J. S. Operant conditioning of visual fixation in infants under visual and auditory reinforcement. Developmental Psychology, 1969, 1, 508-516.

Witkin, H. A., Dyk, R. B., Faterson, H. F., Goodenough, D. R., \& KARP. S. A. Psychological differentiation. New York: Wiley, 1962.

Wood, D. J., \& Shotter, J. S. A preliminary study of distinctive features in problem solving. Quarterly Journal of Experimental Psychology, 1973, 25, 504-510.

Wood, D. J., Shotter, J. S., \& Godden, D. R. An investigation of the relationships between problem-solving strategies, representation and memory. Quarterly Journal of Experimental Psychology, 1974, 26, 252-257.

(Received for publication February 6, 1976.) 